\title{
Bridging Students' Learning Achievement
}

\author{
Maman Suryaman \\ Universitas Singaperbangsa \\ Kawarang, Indonesia \\ drmaman.suryaman1961@gmail.com
}

\begin{abstract}
This paper discussed the ways teachers create an atmosphere of teaching and learning so that they are able to develop the utmost of their potential. The theoretical approach was used to provide an analysis on the process and the learning outcomes as well as the factors that influence it. Learning outcomes is meant as a tool to maintain the dynamics of life in the face of accelerating change both psychologically and economically. The ability to adjust to changes is indication of the performance levels of education. Several views about the concept of learning including the theory of stimulus-response, trait theory, the theory of the constitution, the theory of factors, the classical theory and the theory of reinforcement-operand shared the point that the process of learning requires a condition that allows learners to develop their potential to be able to adjust to the demands and needs. Learning difficulties occurs when selfweakness is assumed and beyond learner circumstances. Teacher behavior, the learner external factor, is a key factor in the creation of learning atmosphere. Teacher's expertise in understanding individual learners and directing them to accept, understand and reach the full potential, help learners determine the level of the atmosphere created in learning. Diagnosing learners' difficulties are also necessary in accordance with the stages so that learners are able to make adjustments on the tasks of development. In conclusion, attitudes and behavior of teachers play an important role in creating a learning environment that supports the development of students' utmost potentials.
\end{abstract}

Keywords- Guidance, Learning Difficulties, Learners' Potential, Teacher Behavior

\section{INTRODUCTION}

Education is defined as a conscious and deliberate effort to create an atmosphere of learning and the learning process so that learners are actively developing their potential to have the spiritual power of religion, self-control, personality, intelligence, noble character, and skills needed him, society, nation and state. The main phrase in the definition is 'create an atmosphere of learning and the learning process', which means how important the role of teachers in education and the learning process are to create a learning atmosphere supportive of the learning outcomes expected. Harmonious, comfortable and fun atmosphere is a prerequisite for the occurrence of a quality learning process.

Learning is a process of behavior change as a result of the experience, which includes knowledge, attitudes and skills. Learned behavior is a provision to maintain a person's survival, armed with the knowledge, attitudes and skills, humans are expected to meet the demanding needs and maintain its survival. We often get caught up in assessing learning outcomes by looking at other educational institutions and the achievement of value for graduates, but we never went deeper into the three domains of learning outcomes (knowledge, attitudes and skills). The main task of teachers and educators is to change the existing potentials of learners into competence, so that graduates are ready to compete in various arenas of life.

The teacher behavior, however, often made the students feel uncomfortable in the learning environment. This is caused by the behavior of teachers that are too high in setting learning goals without seeing the potential and characteristics of learners so it is difficult to achieve. Teachers also look at students' mistakes, pessimistically interpret the learning outcomes, compare students with the other ones, help learners exceedingly, and label learners who are less able to achieve the learning objectives. In this article, I would attempt to describe how teachers behave in creating a learning atmosphere that nurture learners' potential.

\section{LITERATURE REVIEW AND DISCUSSION}

\section{A. Educational Outcomes}

Reference [1] argues that the output of education is graduates, while its outcome are the values of individual and social. Positive values of the individual include (1) pleasure or psychological values, (2) economic value including opportunities to get a job (job opportunity), develops a personality (personality) that impact on the alignment of the way it reacts and interacts with the environment, as well as higher revenue (income), (3) social strata, namely the award of the public. Reference [2] argued that the development of quality human resources is the process of contextual, and thus the development of human resources through education is not limited to preparing people who master the knowledge and skills that not only fit the world of work at the moment, but also human beings who are able, willing and ready to learn throughout life.

According to [3], there are two requirements so that we can achieve a success, namely, rational intelligence and emotional intelligence. Both of these intelligences controlling influence each other in performing an action. We often boast rational intelligence to achieve a college degree, but we forget a lot of scholars who do not have emotional intelligence. He further explains that the progress of modernization spurs people to high levels of depression. Many people are unable to control their emotional intelligence that leads to anarchists, 
offensive manners, blaming others. They always think that failure is due to the actions of others.

For depressed people there are only two choices: fight or flee. When this happens constantly in ourselves, then the social and cultural order which we maintain will be shattered, and there was just chaos in life. We often witness the emotional deterioration that occurs in our young generation, which is characterized by (1) withdrawing from the association, (2) anxiety and depression, (3) having a problem in terms of attention and thinking, and (4) naughty or aggressive behavior [3]. Student brawl, fighting between villages, the use of narcotics is wrong, violent, head-to-quarrel between rival groups, promiscuity, anarchic demonstration, happens in society as a result of the lack of conversation in controlling emotions.

Reference [3] offers a "prescription", that is, think for a moment before acting in response to a threat. Since man has been given by God a complete anatomical structure of the brain, in contrast to reptiles (a type of snake), which is only given weevil brain or mammals (breastfeeding) by humplimbic brain and simple limbic. Reptile is able to think only for survival, so that in case of attack, instinctively, he attacks or flee. Mammal is able to maintain viability and was also given a sense of compassion but was limited to her cub. But people are given by God a brain structure called "neo-cortex", which is used to process the message into a response action. Therefore, if any of us were eating their children in many ways, that's the "reptile". If being very protective of the children and descendants, that is "mammals", and if there is no prudent and wise in all his actions, taking into account the benefits of the world and the hereafter that is "man". Because by nature, man is "nature" of the brain that is perfect instrument, and placed in the highest degree. Life is a choice; either we are reptiles, mammals or appropriate disposition, that is, man.

For human, when there is a threat of "emotional hijacking", the threat message coming from the outside is not processed through the neo-cortex, but directly through the shortcut entry in the brain that ordered the hump and resulted in a physical reaction to perform an action out of control. If this is the case, then what happened is "escape or fight". Both of these conditions equally benefit humans, and can cause humans become incompatible (maladjustment). It also can cause physical damage primarily to the structure of the brain, one of which is the "symptoms of a stroke", and thus we should slow down in response to a threat.

The dynamics of social change is now so out of control. Turbulence (chaos) occurs in many areas of life and sometimes makes us confused to respond. Reference [4] found that the change is permanent with different pace from time to time, whereby the pace is getting faster as the time flows. This is caused by the progress of science and technology, where technology changes over time and continues to grow rapidly, so that the technology cannot be measured through the life of its technical (life time), but measured by its generations, and consequently change the way things work in a revolutionary way [5], [6]. It then raises a question: how do we respond to changes in the revolutionary way of working? Reference [4] conveys the three pillars of change, namely; (1) clarity, that is, we should know clearly where we are going, (2) commitment, which clings to the goal we want to achieve, and (3) capability, which requires skills. We often see the brightest and the best, but not always successful. This is because one does not realize something has happened, that is, change. Therefore we have to be smart in making the best choice in the work and follow its changes. To understand what makes the best of success, we need to understand what they are doing, as well as the thoughts and feelings that gave birth to the action. Regarding the thoughts and feelings that gave birth to the action, according to [4], it was called competence. The underlying elements are not easily seen, but directing and controlling behavior are observable. Social role and self-image lie at the level of one's consciousness, but the character and motives is much below one's consciousness. Therefore the key to the success of a competency will depend on the one's character and motives.

Reference [7] initiated the seven habits of highly effective human (the 7 habits of highly effective people) namely; (1) be pro-active, (2) goal-oriented, (3) set priority, (4) think winwin, (5) try to understand first, understandably, (6) achieve synergies and (7) develop your chainsaw. Pro-active is the opponent of reactive; pro-active is an action (response) and is done on a stimulus that is processed through a process of selfawareness. Reactive, on the other hand, is not based on selfawareness. Reactive people will be very much influenced by the physical environment. For example, when the weather is nice then they are fun. Meanwhile, pro-active people can set their own weather, whether it rains or shines, there is no difference for them. They are driven by value, so that he can produce quality work. Pro-active people will always take the initiative, because our nature is to act and not be the subject of. Taking initiative does not mean urgency, annoying or aggressive, if not destructive. Pro-active indicates intelligence, awareness and empathy, and they put feeling on the second priority after value, so that they can listen to our language.

Advances in science and technology, particularly the field of information and communication technology (ICT), has propelled us into the era of globalization, characterized by a perception that as if the world has not had state borders (borderless line state). With technology, we can know what has happened in other parts of the world in real time. According to [8], the process of globalization moves in line with three areas of human life, namely, economics, politics and culture. Globalization affects the economy in the form of the arrangements for production, exchange of goods, distribution and consumption in the form of goods (goods) and services (services). Globalization in political field is related to the concentration and power applications. The globalization of culture and expression includes the exchange of symbols of the facts, understanding, confidence, tastes, and values.

The process of globalization in these three areas, according to Waters [8], is formed on the dimensions and patterns of ideal. The process of globalization of economics includes the dimension of trade, production, investment, organizational ideology, money market, and the labor market. These dimensions has spawned patterns: (1) absolute freedom in trade, services and commodities symbolic; (2) the production 
of a balance determined by the geographical advantages; (3) foreign direct investment; (4) flexible ideology of organization of the global market; (5) the money market with a decentralized pattern, directly and without national boundaries; and (6) the labor market with workers' freedom of movement patterns.

Globalization in political field includes the dimension of state sovereignty, focus on problem solving, international organizations, international relations, political culture. Political dimensions has spawned pattern of loss of national sovereignty; local issues are always in the global context; very powerful international organization; smooth and multi-centric international relations, political and cultural transcendence with estate values-centric.

Globalization of culture includes the landscape dimension of trust (sacriscape), ethnic landscape (etnoscape), the economic landscape (econoscape), the media landscape (mediascape), and the landscape of relaxation (leisurescape). These dimensions give birth to the pattern: (1) territorial mosaic of religions, (2) territorialism, cosmopolitanism, and ethnic diversity, (3) consumption simulation and representatives of the economy, (4) the distribution of the image (image) and global information, and (5) global tourism.

Communication plays a very important role in the current era of globalization. We need to continue to learn and develop in order to have competence in communication, whether direct communication or indirect communication, body language, and gestures as a determinant of the success rate of direct communication. Mastery of information technology is a decisive factor in the indirect communication. These factors should be mastered in order to increase their capacity to face the competition of life. Communication is a process by which a message is delivered from the source to the receiver. Related to communication, [9] points out the communication model by using the S-M-C-R. A source (Source/S) sends a message (Message / M) through a specific channel (Channel / C) to individual recipients (Receiving/R). The implication is how we do a communication to get the message that we expect, to the recipient with full understanding, and the recipient to perform an action in line with expectations.

Advances in technology only provide a means of more efficient way to move forward or backward. Change is inevitable with a speed that has never been seen by humans. The competition was getting tougher, and thus we should think as "winners" by removing unfounded fears and building confidence and self-image, and digging the greatest abilities and achieving the highest goals [10]. Plato argues that "the first and best victory is self-defeating; defeated by oneself is the most embarrassing thing, and least of all things [10]. Consequently, we have to build self-confidence from now through the ten steps of thought, as [10] noted, namely, (1) winner was not born, but made; (2) the main force of existence is that you are thinking that you have; (3) you are able to create a reality of your own; (4) there are certain benefits which are found in every misfortune; (5) every belief you have is an option; (6) you never defeated, until you accept defeat as a reality, and decided to stop business; (7) you have to have the ability to excel, at least in one of the major areas of your life; (8) the only restrictions of what you can accomplish in your life is a restriction that you apply yourself, (9) there will be no great success without a great involvement; and (10) you need the support and cooperation with others to achieve quality goals.

\section{B. Teacher Behavior}

The warmth of the teacher-student relationship in the learning process not only can provide motivation and foster a desire for success. But it also will improve the social and academic skills [11] [12]. Students' perception of teacher behavior largely determines their self-esteem [13]. The behavior of the teacher in the learning process and learning affects the learning outcomes of students [14]. Unconsciously teacher has behaved differently as perceived by learners (Rosenthal; Karabenick in [14]. Pygmalion effect occurs on students as a result of the imaging of teachers to students, where students who perform well get praise while students who do poorly received reproach. This will demotivate learners instead of encouraging them to learn. More teachers have high expectations of the children who are good, and gave a bad labeling on children who are slow in learning (Myers in [14]. The teacher's task is nonetheless to create an atmosphere so that students develop a superior potency [15].

Ki Hajar Dewantara initiated a short sentence related attitudes and behavior of a teacher namely: Ngarso Ing Sung Tulodo, Madyo Ing Mangun Karso, Tut Wuri Handayani, meaning that a teacher should be in front by example, are central to the creation, at the rear provide motivation [15] Teachers should be role models for their students; they must be ready and willing to sacrifice, and to avoid acts reprehensible. Teachers as educators need to imitate the behavior of the Prophet in preparing future generations, with magnanimity and moral glory, have patience and sincere nature of the act of education and learning .[16]

Reference [17] points out the role of the teacher in the learning process and learning, such as (1) The conservator (custodian) value system and innovator (innovator) science, (2) transmitter (successor) system value to learners, (3) transformer (translator) system value personal development, and (4) the organizer (organizers) educative process. Teachers produce a social work major, fundamental and far-reaching impact in the life of society, nation and state including (1) fundamental, because it helps find the meaning of life, patterns of behavior, patterns of cultural value corresponding social demands; (2) development of learners that includes cognitive, affective and psychomotor; (3) The continuous selfdevelopment, where teachers help improve consistency, activities and supporting facilities; (4) controls the negative factors affecting the life, both internal and external; (5) to help the maturation process of self; (6) developing creativity; and (7) a balancing of social and cultural situations [18]

Every teacher hopes that learners acquire satisfying and good learning outcomes. But such expectations often run aground and could not be realized. Many students who have failed in learning are characterized by symptoms such as low learning achievement, low learning results, unacceptable 
behavior, lying, laziness, and bullying. Those students need guidance in terms of tutoring, social assistance and personal counseling [15]. Winkel in [15] states that the guidance is given so that learners are able to know themselves and understand how to overcome personal problems that interfere with learning.

\section{Learning Difficulties}

Some learning theories advanced by experts, including Dollar and Miller's Stimulus - Response theory (S-R), Gordon Allport's trait theory, Sheldon's theory of the constitution, factors of Cattell's theory and the theory of Skinner's operant reinforcement. Dollar and Miller's Stimulusresponse theory purports that learning takes place under certain psychological principles; the study should want something, pay attention to something, do something, and gain something. Brief factors in the study were the impetus, cues, responses, and gifts [19]. Conflict occurs when the response away from the goal (Dollar and Miller in [19]. Learning has meaning when teachers set a too high goals while student response is too low. This will cause conflict and demotivate students. Thus, teachers must understand students' readiness for entering the material to be studied (the entry behavior). Before learning, teachers must first conduct preliminary tests, to determine the readiness of student learning. Thus, the target learning outcomes is relevant to the students' learning ability.

Gordon Allport's theory of nature, gives us that humans are a very unique and different from each other. One's personality structure and dynamics are driven by the disposition of the cardinal, central and secondary. This theory says that what one does is the key to an important clue how people behave today. Intention is the expectations, desires, ambitions, aspirations and plans of anyone. Consider that the functional autonomy of adult's multifarious motives and behavior of a person can be an end in itself, although it was originally done for other reasons. Expressive and consistent behavior are important because they show the embodiment of personal deepest layers. There are two components in any human response, namely, adaptive component and expressive component. Adaptive component concerns the value or benefit of action, the impact and the goals to be achieved. Expressive component is a force in the commission of that [19].

The theory of the constitution thinks that the psychological aspects of behavior is associated with morphological and physiological human. Individual aspects are relatively fixed and unchanging including morphology, physiology, endocrine function, and can be contrasted with those aspects that are relatively unstable and easily change due to environmental stresses, such as customs, social attitudes and education [19]. Sheldon classifies human nature into three types, namely, viskerotonia, somatotonia, and serebrotania. Viskeratonia have characteristics like comfort, relationships, food, people and affection. Somatotonia have a physical adventure that trait, likes to take risks, aggressive, insensitive to the feelings of others, like a fuss. The important thing for him is action, strength and power. Kretschmer in [19] as a precursor to Sheldon, classifies human physical type that characterizes behavior into four types, namely, aestenis type, athletic, piknis and dysplastic. Aestenis with frail and linear posture is a combination of physical with less fat and an average height of tall, skinny thin and seemed higher than actual, narrow shoulders with thin arm muscular thin, a long, narrow, flat chest, and sharp ribs and thin belly. Athletic has the physical characteristics such as muscular and powerful, of medium to high, very broad shoulders and jutting, strapping chest, a strong stomach, torso tapered at the bottom, hips and legs look lovely with wide shoulder. Piknis mode characterized by enlargement of the head, chest and abdomen, medium stature with a round body figure, short necks and huge, curved in the chest and lower body width. Dysplastic type shows a strange posture of body.

Factor theory of Cattell assume that human behavior consists of common factors and special factors. Common factors includes fluency, general intelligence, and education. Special factors such as visual memory, perception of space and specialized information. According to this theory personality is something that allows predictions about what someone needs to do in certain situations. Personality serves as a structure of complex traits and is distinguished, whose motivation depends on the dynamics of its group (dynamic traits). Personality is a mental structure that infers on the basis of observable behavior that explains the order and the provisions in the act [19]. The dynamic nature can be classified into natural ability and temperament characteristics. Personality traits is the ability that determines the effectiveness in achieving goals. While the nature of the response is determined by the temperament of the constitutional influences such as speed, energy, or emotional reactivity. The dynamic properties include attitude, ergs and sentiments. Attitudes of individuals in certain situations show interest with particular intensity to perform a series of actions on an object. Erg is a biological drive, whereas sentiment is a learned attitude structure.

Three types of learning studied by Cattell consist of classical conditioning, instrumental conditioning and learning integration. Classical conditioning tries to associate a response to environmental cues, while the instrumental conditioning is a means to the satisfaction of the erg. In other words, it explains how to build dynamic relationships between attitudes and sentiment in order to satisfy the erg to build dynamic grating or confluence learning. In this type of learning integration, individuals learn to maximize long-term total satisfaction with a number of erg channel at a given time, while restrain suppresses or sublimates others [19].

Skinner's theory is operant reinforcement. Skinner assured on the assumption that human behavior runs according to law. Thus, he seeks how to manipulate the conditions that affect or result in changes in behavior. Skinner developed the functional analysis of behavior based on the analysis of causality. Human behavior is in order and the main purpose of our control. The best control is to find the relationship between the devout hope of independent variables, the dependent variable of the organism then takes control by manipulating the same input in order to obtain a specific output [19]. 
Burton in [17] identifies students who are suspected of having learning difficulties, as indicated by the failure of students in achieving the learning objectives. Students are said to fail in learning when (1) do not reach the size of a minimum success rate within the time limits prescribed; (2) cannot do or achieve when compared with the ability, talent or incorporated intelligence (under-achiever); (3) cannot realize the development tasks; and (4) did not achieve the required mastery as prerequisites for next level (prerequisite).

\section{Guidance}

Some of the factors that affect the teaching and learning process by Loree includes (1) the stimulus or learning variables, (2) organismic variables, and (3) response variables [17]. Stimulus includes a learning experience and environmental variables. Learning experience variables include methods and task variables. Method variables concerning the motivation to learn, intensive guidance of teachers, the opportunity, and strengthening (reinforcement). While the task variables include interest, meaningfulness and appropriateness. Organismic variables include characteristic of learners, mediating processes, and response variables. Characteristic of learners consists of intelligence level, age, level of maturity and readiness to learn. Mediating processes includes perception, motivation, fear, anxiety, physical, psychological stress and the like. While in the response variables formulas include objectives that include domains of cognitive, affective and psychomotor.

Burton in [17] points out some weaknesses in the study which includes two factors, namely, weakness on students and situations beyond the student. Weakness on students include physical weakness, mental weakness, emotional weakness, and the weakness of attitudes and habits. Physical weakness consists of nervous system function resulting in emotional disturbance, senses that makes it difficult to interact, the balance that causes developmental and reproductive disorders, disability, often leading to less stable emotions, and chronic diseases that hamper efforts to learn. Emotional weakness include discomfort (insecurity), one custom (maladjustment) against the people, the situation, the demands of the task and the environment, phobias which consists of hate, fear, antipathy as a self-defense reaction, and immaturity. The weakness caused by the attitudes and habits include low interest, too much activity outside the context of learning that leads to unwillingness to learn, failure to concentrate, less cooperative and avoid responsibility, unmotivated learning, ditching, and nervous. The situation outside the student in school and community environments include, among others, curriculum uniformity which denies individual differences, administrative standards, assessment, and learning experiences, teachers' teaching workload, class population, the condition of the family, extracurricular activities and the adequacy of food.

Ross and Stanley in [17] developed five questions in performing diagnostic learning difficulties, namely, (1) who are the pupils having trouble?; (2) where are the errors located?; (3) why are the errors occur?; (4) what remedies are suggested?; And (5) How can the errors be prevented? Thus the steps that can be done are (1) identification of cases, the marking of students suspected of having learning difficulties, (2) the identification of the problem, namely the mark and localize where lies the difficulty of learning, (3) identification of the causes of the difficulties, which marks the types and characteristics of trouble and a contributing factor, (4 ) prognosis, the conclusions and decisions and foresee the possibility of a cure, and (5) recommendations to make suggestions for solution.

Robinson in [20] suggests that failure of students in learning is caused by the inability to know himself, to understand himself, to accept his situation, to direct himself, to realize all its potential, and the behavior of one custom (maladjustment). Sensory signification of a phenomenon that can be understood can lead to the effect that elicits courage, chivalry, fear and gentleness clamp. Therefore the service can be provided in the form of gathering information about students, providing information about the students, the placement in the appropriate position (subjects, study groups, other activities), information to build understanding and confidence, and continued efforts for the betterment of the students [17].

Schnieders in [18] defines adaptation as a process of mental and behavioral responses of individuals in addressing the needs, tension, conflict and frustration. According to him, one type of adjustment includes adjustment of personal, social and vocational. Social adjustment was strongly influenced by physical condition, development and maturation, psychological, environmental, and cultural.

Some of the principles that form the motivation according to Newcomb [21] is (1) the perceived behavior associated with the creation of encouragement, hungry for seeing the bread; (2) after having something, the willingness to have another as part of previous successes such as feeling hungry after looking bread and want to drink milk after eating bread; (3) a new motive appears after the encouragement is obtained, for example, after seeing the bread, one continues to drink milk to reduce hunger; the desire to obtain bread also appears.

The main task of the teacher is to create an atmosphere of learning so that students are able to develop their potential. To achieve that, teachers need to have the ability to understand the circumstances of his students, so they can provide service in accordance with the conditions and the ability of his students. Preventive activities in anticipation of failure would be better than curative activities to resolve the problem. To develop services, teachers need to understand the strengths and weaknesses of their students so as to put the students in the appropriate position and is able to develop the potential optimally.

\section{CONCLUSION}

Learning is a process of personal change in behavior or a person based on practice or experience. Many factors affect the success of learning such as internal and external factors. The internal factor is a physiological and psychological condition of the students. External factors are classified based on the environment and learning situations. Environmental situations consist of physical and social environment. 
Teachers are part of the social environment that affects the learning interactions.

Learning difficulties occur when learners are not able to adjust themselves to the situation and the demands of learning. Factors causing incorrect behavior treatments (maladjustment) of learners come from themselves or the social environment (including teachers). The phenomena appear as fear, anxiety, and decreased interest in learning, ditching, or not doing their jobs. The teacher's task is to create an atmosphere that encourages interest, meaningfulness, and appropriateness. Behaviors and patterns of action in relation to learning from a teacher will determine the success rate of student learning adjustment.

Counseling begins with diagnosing the causes of children's learning difficulties. Furthermore, students are facilitated to understand themselves, accept themselves and actualize the potential optimally, so that the achievements are relevant with the demands of learning objectives and the potential of the students.

\section{REFERENCES}

[1] E. Cohn, The Economic of Education., Massachusetts: Ballinger Publishing Company., 1979.

[2] S. Kartadinata., Landasan Landasan Pendidikan Sekolah Dasar, Jakarta: Departemen Pendidikan da Kebudayaan, 1997.

[3] D. Goleman, Emotional Intelligence (EdisiBahasa Indonesia)., Jakarta: PT Gramedia Pustaka Utama. , 1999.

[4] Nick Boulter et al., People and Competencies: The Routeto Competitive Advantage, London: Kogan Page Limited, 2003.

[5] G. M. Scott, Prinsip-prinsip Sistem Informasi Manajemen (EdisiBahasa Indonesia)., Jakarta: PT Raja GrafindoPersada., 1994.

[6] Murdick, et al, Sistem Informasi Untuk Manajemen Modern., Jakarta: Erlangga, 1997.

[7] S. Covey, The 7 Habits of Highly Effective People, (Indonesia Version., Jakarta: Binarupa Aksara., 1997.

[8] H. Tilaar, Pengembangan Sumber Daya Manusia dalam Era Globalisasi., Jakarta: Grasindo, 1997

[9] Shoemaker, E. M.; Rogers F.F., Communication of Innovation: A CrossCultural Approach., London: Collier Macmillan Publisher., 1971.

[10] W. Staples, Think Like a Winner (EdisiBahasa Indonesia)., Jakarta: Pustaka Tangga, 1994.

[11] J. Comer, "Schools that develop children.," The American Prospect, vol. 12, no. 7, pp. 30-35, 2001.

[12] O’Donnell, J., Hawkins, J. D., Catalano, R. F., Abbot, R. D., \& Day, L. E, "Preventing school failure, drug use, and delinquency among low-income children: Long-term intervention in elementary schools.," American Journal of Orthopsychiatry,, vol. 65, no. 1, p. 87, 1995.

[13] Kususanto P.;Ismail, H. N.; Jamil, H., "Students" Self Esteem and their Perception of Teacher Behavior: A Study Between Class Ability Grouping," Electronic Journal of Research in Educational Psychology, vol. 8, no. 2, pp. 707-724, 2010.

[14] Z. Ismail, "Student Self Esteem and Their Perception of Teacher Behavior: A Study of Class Grouping System in Pakistan.," International Journal of Business and Social Science., vol. 2, no. 16, pp. 103-113, 2011.

[15] Kosasi; Soetjipto, ProfesiKeguruan., Jakarta: Rineka Cipta, 2009.

[16] A. an-Nahlawi, Prinsip-prinsip dan Metode Pendidikan Islam., Bandung: CV. Dipenogoro, 1996.
[17] A. Syamsuddin, Psiokologi Kependidikan, Bandung: Remaja Rosdakarya, 2007.

[18] H. Agustiani, Psikologi Perkembangan, Bandung: Refika Aditama, 2006.

[19] Supratiknya, Teori-toeri Sifat dan Behavioristik, Yogyakarta: Kanisius, 2001.

[20] Y. Purwanto, Psikologi Kepribadian, Bandung: Refika Aditama, 2011.

[21] S. Santoso, Teori-teori PsikologiSosial, Bandung: Refika Aditama, 2010. 